\title{
EL DEBER DE COHERENCIA Y COOPERACIÓN EN EL EJERCICIO DE LA CONDICIÓN SIMPLEMENTE POTESTATIVA, SUSPENSIVA Y PENDIENTE*
}

\author{
THE DUTY OF COHERENCE AND \\ COOPERATION IN THE EXERCISE \\ OF THE DISCRETIONARY, SUSPENSIVE \\ AND PENDING CONDITION
}

\author{
Fernando Pico Zúñiga** \\ Fecha de recepción: $1^{\circ}$ de abril del 2013 \\ Fecha de aceptación: 31 de julio del 2013
}

\section{Para citar este artículo / To cite this article}

Pico Zúñiga, Fernando, El deber de coherencia y cooperación en el ejercicio de la condición simplemente potestativa, suspensiva y pendiente, 127 Vniversitas, 127-308 (2013) doi:10.1144/Javeriana.VJ127.dcce

* Producto parcial de la investigación en el principio de buena fe y tolerancia aplicado en las obligaciones y los contratos, que el autor adelanta en el marco del Máster en Derecho de la empresa y de los negocios de la Universidad de Barcelona (España).

** Abogado de la Pontificia Universidad Javeriana (Bogotá, Colombia). Candidato al Máster en Derecho de la empresa y de los negocios de la Universidad de Barcelona (España). Se ha desempeñado como monitor de la cátedra de Títulos Valores de la Pontificia Universidad Javeriana (Bogotá, Colombia) y profesor invitado en el área de Derecho comercial de la Facultad de Derecho de la Universidad Sergio Arboleda. Coautor del libro "Solidarismo contractual. El deber de cooperación y su repercusión en la responsabilidad civil." y autor de artículos investigativos publicados en revistas como Universitas Estudiantes y Elementos de Juicio de Bogotá, Colombia. Columnista online del periódico Ámbito Jurídico. Contacto: fpz14@hotmail.com 


\section{RESUMEN}

El principio de la buena fe ha sido y es, sin lugar a dudas, un instrumento legal, eficaz e idóneo para solucionar lo que desde tiempo atrás la ciencia jurídica ha identificado como la "crisis del contrato", que no es otra cosa que la crisis de sus presupuestos - la autonomía de la voluntad contractual y la libertad para contratar-. Así como la defensa a ultranza de los presupuestos clásicos del derecho privado ha generado el problema en mención, el amparo a ultranza de la buena fe bajo ciertas hipótesis puede forjar por contera la conservación de situaciones inverosímiles e injustas dentro del iter contractual. De ahí que sea necesario establecer presupuestos que permitan una favorable aplicación del principio y, particularmente, de los deberes colaterales que emanan de la denominada buena fe objetiva. En ese sentido, el presente documento investigativo pretende esclarecer si, a la luz de los deberes de cooperación y coherencia, la parte obligada debe realizar la fracción de la condición simplemente potestativa, suspensiva y pendiente que ha pactado con su co-contratante. De acuerdo con ese planteamiento, se concluye que de conformidad con los postulados de la buena fe objetiva, las expectativas legítimas fundadas en el co-contratante y del artículo 1538 del Código Civil colombiano, presupuestos verificables por el juzgador en el caso concreto, el obligado deberá cumplir la fracción de la condición que le corresponde so pena de generar perjuicios en la otra parte.

Palabras clave autor: Principio de la buena fe, buena fe objetiva, deberes secundarios de conducta, deber de coherencia, deber de cooperación, obligación condicional, condición, condición simplemente potestativa, legítima expectativa.

Palabras clave descriptores: Buena fe (Derecho), condiciones (Derecho), expectativas (Derecho). 


\section{ABSTRACT}

The principle of good faith has been and is, without doubt, a legal, effective and appropriate tool to solve what legal science identified long ago as the "crisis of the contract", which is nothing but the crisis in their assumptions of the contractual autonomy will and freedom to contract. Just as the unyielding defense of budgets of the classic private law has generated the problem in question, the uncompromising support of good faith under certain assumptions can forge the conservation of improbable and unjust situations within the contractual process. Hence it is necessary to establish premises that allow for a successful application of the principle, and particularly the collateral duties emanating from the so-called objective good faith. In that sense, this research paper aims at clarifying whether, in light of the duties of cooperation and consistency, the obligor must perform simply the fraction of the discretionary, precedent and pending condition he has agreed with its co-contractor. According to this approach, it is concluded that in accordance with the postulates of objective good faith, legitimate expectations based on the co-contractor and the Article 1538 of the Colombian Civil Code, verifiable premises by the judge in the case, the required must meet the fraction of the rightful status applicable to him under penalty of causing damage in the other party.

Keywords author: Principle of good faith, objective good faith, secondary duties of conduct, duty of consistency, duty of cooperation, conditional obligation, condition, discretionary condition, legitimate expectation.

Keywords plus: Good faith (Law), conditions (Law), expectancies (Law).

\section{SUMARIO}

INTRODUCCIÓN.- I. LOS DEBERES DE COHERENCIA Y COOPERACIÓN, MANIFESTACIÓN DE LA BUENA FE OBJETIVA EN LOS NEGOCIOS JURÍDICOS.- $A$. El principio de la buena fe en los negocios jurídicos.- B. La buena fe objetiva.- $C$. El deber de coherencia.D. El deber de cooperación.- II. PRINCIPALES PRESUPUESTOS DE LA CONDICIÓN SIMPLEMENTE POTESTATIVA DE CARÁCTER SUSPENSIVO.- A. Condición simplemente potestativa.- B. Condición suspensiva.- III. EL DEBER DE COHERENCIA Y COOPERACIÓN EN LA EJECUCIÓN DE LA CONDICIÓN SIMPLEMENTE POTESTATIVA.- CONCLUSIÓN. 


\section{INTRODUCCIÓN}

El principio de la buena fe siempre ha existido en el derecho, no de la forma como se entiende en nuestros días, ni mucho menos con la trascendencia y manera con la que en la actualidad se aborda y aplica, en razón a lo que, de varios años atrás, la doctrina ha identificado como "la crisis del contrato", pero sin duda ha sido y es fuente notable de las reglas que gobiernan las conductas humanas y sus negocios ${ }^{2}$.

En efecto, anota Romain, citado por Gustavo Ordoqui, que en el siglo XIX se presentó una desvalorización de la buena fe, ya que se procuró honrar la autonomía de la voluntad tratando de entender la acción humana desde un enfoque netamente individualista. Desde esa perspectiva, se pensó que el juez debía darle preferencia única y exclusivamente al querer de las partes y sus interpretaciones ${ }^{3}$. Fue tiempo después cuando Demogue, en su Tratado de las obligaciones, resaltó las exageraciones del individualismo y señaló que si bien se debe respetar la autonomía de la voluntad, esta no es la única ni el más preponderante elemento del contrato, del cual debe admitirse también, entre otros, la colaboración entre el deudor y el acreedor, la diligencia para el cumplimiento de la obligaciones y la abstención de abusar de los propios derechos ${ }^{4}$.

Se muestra así la gran e incansable dicotomía entre la buena fe contractual y la autonomía de voluntad privada de ultranza, con la que se enfrentan el juzgador y el especialista jurídico ${ }^{5}$, determinante en campos como el de la interpretación e integración de los

1 C. Massimo Bianca, Derecho civil, 3 Contrato, Ed. Universidad Externado de Colombia, 55 y ss. (2007).

2 Ver: José Luis De Los Mozos, El principio de la Buena Fe, Sus aplicaciones prácticas en el derecho civil español, Ed. Bosch, 81 y ss. (1965); Nelly Dora Louzán De Solimano, La buena fe en el derecho romano en: Tratado de la buena fe en el Derecho, Tomo I, Ed. La Ley, 79 (2004); Viviana Kluger, Una mirada hacia atrás: de Roma a la codificación. El recorrido histórico de la buena fe, en: Tratado de la buena fe en el derecho, op. cit., 87 y ss.

3 Jean Francois Romain, Théorie critique du principe générale de bonne foi en droit privé, Ed. Bruylsant, Bruxelles, 135 (2000). Ver también: Demolombe, Cours de droit civil, T. XII, No. 387 (1968).

4 René Demogue, Traité des obligations, T. VI, 5 y ss. (1931). Vid. De Page, Traité elementaire de droit civil, T. II, 431 (1964).

5 Por ello afirma Luis Diez-Picazo en el prólogo de la obra intitulada El principio general de la buena fe del autor alemán Franz Wieacker, "El principio de la buena fe comporta, pues, una serie de limitaciones de los derechos subjetivos". Franz Wieacker, El principio general de la buena fe, Ed. Civitas S.A., 19 (1997). 
contratos — criterio subjetivo y objetivo_-, el cumplimiento de las prestaciones y la responsabilidad civil, por enunciar algunos.

De este modo, la delimitación del concepto de buena fe se torna en una tarea capital, pues es desde allí donde nace el entendimiento que guía el sentido de la aplicación del principio en el caso concreto, en los campos contractuales enunciados. Así, ha dicho la Corte Constitucional colombiana que la buena fe se manifiesta de diferentes maneras ${ }^{6}$, y ha explicado, en razón al concepto de buena fe, que

La jurisprudencia constitucional ha definido el principio de buena fe como aquel que exige a los particulares y a las autoridades públicas ajustar sus comportamientos a una conducta honesta, leal y conforme con las actuaciones que podrían esperarse de una "persona correcta (virbonus)". Así la buena fe presupone la existencia de relaciones reciprocas con trascendencia jurídica, y se refiere a la confianza, seguridad y credibilidad que otorga la palabra dada ${ }^{7}$.

En igual sentido, ha destacado la Sala de Casación Civil de la Corte Suprema de Justicia nacional, en lo que al alcance del principio en el campo contractual refiere, que la buena fe "presupone que se actúe con honradez, probidad, honorabilidad, transparencia, diligencia, responsabilidad y sin dobleces"”. De este modo, se ha entendido que

[1] a buena fe [...] se torna bifronte, en atención a que se desdobla, [...] en la apellidada "buena fe subjetiva" (creencia o confianza), al igual que en la "objetiva" (probidad, corrección o lealtad), sin que por ello se lesione su concepción unitaria que, con un carácter más panorámico, luce univoca de cara al ordenamiento jurídico. Al fin y al cabo, [...] es un principio general - e informador - del derecho, amén que un estándar o patrón jurídicos, sobre todo en el campo de la hermenéutica negocial y de la responsabilidad civil ${ }^{9}$.

Así, la buena fe objetiva trasciende el estado psicológico, propio de la denominada buena fe subjetiva, y se traduce en una norma o regla orientadora del comportamiento que concierne, in concreto, a los deberes colaterales - deberes de información, solidaridad, secreto, coherencia- los cuales se trazan e incorporan al iter con-

6 "La Corte advierte, como primera medida, que el concepto de 'la buena fe' se manifiesta de diferentes maneras". Corte Constitucional de Colombia. Sentencia C-007 de 2002.

Corte Constitucional de Colombia. Sentencia C-1194 de 2008.

8 Corte Suprema de Justicia. Sala de Casación Civil. Exp. 6146 (2 de agosto de 2001).

9 Ibíd. 
tractual, como indica el artículo 1603 del Código Civil colombiano (de ahora en adelante C.C.), y que en nuestro ámbito han menguado, hasta cierto punto, la crisis de la autonomía de la voluntad y la libertad contractual.

La confianza y la colaboración son tal vez dos de los más importantes presupuestos axiológicos de la buena fe como principio general de derecho. La expresión jurídica de la confianza ha sido consagrada de antaño en la máxima romana venire contra factum propium non valet, que también tiene una expansión en el campo de la buena fe a través del denominado deber de coherencia, por mencionar la que interesa ${ }^{10}$. De igual manera, la cooperación entre las partes en el ejercicio diario de la vida y particularmente en el ámbito contractual no ha sido ajena al desarrollo jurídico; autores como el ya mencionado Demogue y Betti resaltaron la importancia de la colaboración entre los contratantes para la consecución de los fines comunes determinados en el acuerdo contractual, y en esa medida desde la buena fe objetiva sobresale el deber de cooperación entre las partes, quienes deben colaborar a su co-contratante a lo largo de la vida del contrato.

La coherencia exige, tras la generación de confianza en la otra parte, una sucesión lógica de actos que se estiman previsibles. La cooperación reclama, con fundamento en el acto jurídico celebrado, obrar solidariamente con el co-contratante en procura de conseguir el fin acordado. De este modo, en la etapa pre-negocial, bajo la hipótesis de la existencia de una condición potestativa, surge un interrogante sumamente interesante y trascendental de cara al deber de coherencia y las acciones de los contratantes. En la hipótesis de la existencia de un obligación sujeta a condición simplemente potestativa de carácter suspensiva, ¿está obligada la parte, la que tiene sobre su voluntad el ejercicio de la condición simplemente potestativa, a desplegar su conducta en procura del cumplimiento de la condición, porque así se lo exigen los deberes coherencia y cooperación? En otras palabras, ¿en virtud de los deberes de cooperación y coherencia quien debe cumplir la condición

10 Mariana Bernal Fandiño, El deber de coherencia en los contratos y la regla del venire contra factum proprium, en: Quaestiones Disputatae, No. 1, Ed., Pontificia Universidad Javeriana, 13 y ss. (2010). 
simplemente potestativa está obligado a ejecutar la fracción que le corresponde de ella?

Para resolver el interrogante sugerido se propone la siguiente estructura de análisis que se encaminará a resolver la cuestión. En primera instancia, se abordarán someramente los deberes de coherencia y cooperación como manifestaciones de la buena fe objetiva; en segundo lugar, se tratarán los presupuestos jurídicos de la condición simplemente potestativa; como tercer punto, desde el campo propositivo, se presentará la relación entre el deber de coherencia y la condición simplemente potestativa con el objetivo de darle solución a la pregunta planteada a través de la aplicación de determinados criterios y, por último, se mostrará una conclusión.

\section{LOS DEBERES DE COHERENCIA Y COOPERACIÓN, MANIFESTACIÓN DE LA BUENA FE OBJETIVA EN LOS NEGOCIOS JURÍDICOS}

Para entrar a analizar el deber de coherencia se estima necesario realizar un breve repaso por temas como la buena fe y, particularmente, la buena fe objetiva, preponderantes e íntimamente relacionados con el asunto que se trata. Se pasa a estudiarlos.

\section{A. El principio de la buena fe en los negocios jurídicos}

Como indica Mosset Iturraspe, la buena fe es mucho más que lo contrario de la mala fe ${ }^{11}$. En efecto, "actuar de buena fe no solo es ausencia de malicia sino actuar con diligencia, colaboración, lealtad. No alcanza con las buenas intenciones sino que se debe actuar con prudencia y diligencia"12.

De este modo, ha dicho la Sala de Casación Civil de la Corte Suprema de Justicia colombiana que el

[...] principio vertebral de la convivencia social, como de cualquier sistema jurídico, en general, lo constituye la buena fe, con sujeción a la cual deben actuar

11 Mosset Iturraspe, Contrato simulado y fraudulento, T. II, 14 (2001).

12 Gustavo Ordoqui Castilla, Buena fe contractual, Ed. Pontificia Universidad Javeriana - Universidad Católica de Uruguay - Ibáñez, 174 (2012). 
las personas — sin distingo alguno — en el ámbito de las relaciones jurídicas e interpersonales en las que participan, bien a través del cumplimiento de deberes de indole positiva que se traducen en una determinada actuación, bien mediante la observancia de una conducta de carácter negativo (típica abstención), entre otras formas de manifestación. Este adamantino axioma, insuflado al ordenamiento jurídico — constitucional y legal - y, en concreto, engastado en un apreciable número de instituciones, grosso modo, presupone que se actúe con honradez, probidad, honorabilidad, transparencia, diligencia, responsabilidad $y$ sin dobleces. Identificase entonces, en sentido muy lato, la bona fides con la confianza, la legítima creencia, la honestidad, la lealtad, la corrección y, especialmente, en las esferas prenegocial y negocial, con el vocablo "fe", puesto que "fidelidad, quiere decir que una de las partes se entrega confiadamente a la conducta leal de la otra en el cumplimiento de sus obligaciones, fiando que esta no lo engañará"13.

Es incuestionable el sustancial valor de la buena fe en el desarrollo de las actividades humanas y, por supuesto, en sus negocios. $\mathrm{Su}$ importancia, como han sostenido con claridad meridiana De Los Mozos, Trazegnies y Ordoqui, entre otros, radica precisamente en el hecho de que la buena fe opera como una vacuna frente a la deslealtad, el cinismo y la deshonestidad en los negocios jurídicos, donde se impone para asegurar la convivencia pacífica y justa entre los contratantes ${ }^{14}$.

Es así como la Corte Constitucional ha manifestado que el principio de la buena fe "exige a los particulares y a las autoridades públicas ajustar sus comportamientos a una conducta honesta, leal y conforme con las actuaciones que podrían esperarse de una 'persona correcta (virbonus)'"'15.

Al amparo del artículo 83 de la Carta Política de nuestro país, la consagración constitucional y positiva del principio de la buena fe "significa su incorporación en todas las leyes y en todos los contratos, tanto de derecho público como de derecho privado" ", arropando cada una de las actuaciones de las personas, de imperioso cumplimiento en la celebración, ejecución e interpretación de sus actos y negocios jurídicos.

\footnotetext{
13 Corte Suprema de Justicia. Sala de Casación Civil. Exp. 6146. (2 de agosto del 2001).

14 Gustavo Ordoqui Castilla, Buena fe contractual, op. cit., 107 y ss.

15 Corte Constitucional de Colombia. Sentencia C-1194 de 2008.

16 Lord Mansfield, El concepto de la buena fe en los contratos, Revista de la Academia Colombiana de Jurisprudencia, No. 324, 27 (diciembre del 2003). Ver también: Arturo Valencia Zea \& Álvaro Ortiz Monsalve, De las obligaciones, Tomo III, Ed. Temis, 158 y ss. (2010).
} 
Proyectado al universo del negocio jurídico, el principio de la buena fe demanda que los contratantes se comporten y desempeñen durante todo el contrato de manera honesta, proba, honorable, transparente, diligente, responsable y "sin dobleces", como dice nuestra Corte Suprema de Justicia ${ }^{17}$, desprovistos del interés de romper el equilibrio prestacional.

Nuestro Código de Comercio expresa en el artículo 871 la dimensión del principio de la buena fe en el campo contractual, al señalar que "Los contratos deberán celebrarse y ejecutarse de buena fe y, en consecuencia, obligarán no solo a lo pactado expresamente en ellos, sino a todo lo que corresponda a la naturaleza de los mismos, según la ley, la costumbre o la equidad natural", normativa que no solo se ha utilizado in concreto en los contratos comerciales, sino que ha servido de premisa para encontrarle sentido y alcance al principio de la buena fe en el campo de las relaciones obligacionales. En efecto, la Sala Civil de la Corte Suprema de Justicia así lo ha reconocido al afirmar:

[...] la buena fe se vislumbra como un genuino hontanar de normas de comportamiento no formuladas positivamente pero implícitas en el ordenamiento que, por consiguiente, ante una situación dada, le imponen al sujeto una conducta determinada con miras a no agraviar los intereses jurídicos ajenos. Desde este punto de vista, la buena fe genera deberes y se califica cotejándola con un prototipo abstracto colocado en el contorno social de la persona.

Refiriéndose a estos aspectos de la buena fe, ha dicho esta Corporación que "en tratándose de relaciones patrimoniales, la buena fe se concreta, no solo en la convicción interna de encontrarse la persona en una situación jurídica regular, aun cuando, a la postre, asíno acontezca, como sucede en la posesión, sino también, como un criterio de hermenéutica de los vínculos contractuales, amén que constituye un paradigma de conducta relativo a la forma como deben formalizarse y cumplirse las obligaciones" [...] $]^{18}$.

Por otro lado, el artículo 1603 del Código Civil dispone que los contratos "obligan no solo a lo que en ellos se expresa, sino a todas las cosas que emanan precisamente de la naturaleza de la obligación o que por ley pertenecen a ella"; es decir, para que un contrato sea ejecutado de buena fe es indispensable cumplir con todas las obligaciones que se derivan de este, incluyendo aquellas que las partes

17 Corte Suprema de Justicia. Sala de Casación Civil. Exp. 6146 (2 de agosto de 2001).

18 Corte Suprema de Justicia. Sala de Casación Civil. Exp. 5372 (9 de agosto de 2000). 
no pactaron pero que se encuentran en la ley, cuya observancia es presupuesto necesario para la validez y ejecución de toda obligación convencional. En este sentido, y en atención a lo dispuesto por los artículos 1501, 1603 y 1621 del Código Civil, el profesor Ospina Fernández señala:

[...] los actos jurídicos pueden y suelen producir efectos que se atribuyen al querer de los agentes, aunque estos no los hayan previsto y, todavía más, aunque hayan tenido la intención positiva de descartarlos. Desde el momento en que los particulares usan la facultad que la ley les confiere de participar en la función reguladora de las relaciones sociales, mediante la realización de actos jurídicos, se presume que dichos particulares no solamente han querido los efectos provistos por ellos, sino también todos aquellos que la ley misma les atribuye, por vía imperativa o supletiva de la voluntad, y habida cuenta de la naturaleza de tales actos, como también todos los efectos que emanan de las cláusulas que son de uso común en actos de la misma índole ${ }^{19}$.

Así, la buena fe irradia la teoría del negocio jurídico desde tres aristas, a saber: (i) la buena fe subjetiva; (ii) la buena fe objetiva o regla de conducta y (iii) la buena fe como regla de hermenéutica, como lo reconoce la Corte Suprema de Justicia:

[...] la noción de buena fe suele ser contemplada desde tres perspectivas distintas: en primer lugar, aquella que mira el interior de la persona y, por ende, toma en cuenta la convicción con la que esta actúa en determinadas situaciones; en segundo lugar, como una regla de conducta, es decir como la exigencia de comportarse en el tráfico jurídico con rectitud y lealtad; y, finalmente, como un criterio de interpretación de los contratos ${ }^{20}$.

\section{B. La buena fe objetiva}

Sin adentrarse en el análisis de la buena fe subjetiva y la buena fe como instrumento de interpretación, asuntos que no son de interés de cara al estudio concreto propuesto, la buena fe objetiva obliga a cada contratante a actuar con lealtad con su co-contratante y

19 Guillermo Ospina Fernández \& Eduardo Ospina Acosta, Teoría general del contrato y del negocio jurídico, Ed., Temis, 27 (2000).

20 Corte Suprema de Justicia. Sala de Casación Civil. Expediente 1997-9124 02 (2 de febrero de 2005).

Ver también: Corte Suprema de Justicia. Sala de Casación Civil. Exp. 254.01 (9 de agosto de 2007). 
con el negocio mismo, lo que le impone el deber de no limitarse a cumplir simplemente con lo que literalmente se ha estipulado, sino a ir más allá de los textos acordados, con el sincero propósito y la obligación moral y legal de que, mediante el cumplimiento de todas sus obligaciones, el co-contratante logre los legítimos propósitos jurídicos y económicos que persigue con la celebración del acto jurídico.

Porque el deber de cada parte en el negocio jurídico no se limita o se agota con el cumplimiento al pie de la letra de los incisos contractuales, sino que se extiende a todas aquellas cosas que - por la propia naturaleza de los negocios - hagan posible su efectiva realización y la obtención de los fines que se persiguen con su celebración por todas las partes, por la lealtad que cada uno debe a su co-contratante y al contrato mismo o por la buena fe con que se debe actuar en el terreno contractual.

Esta dimensión del principio de la buena fe corresponde a la denominada buena fe objetiva, con arreglo a la cual la buena fe y los deberes que de ella emanan deben ser entendidos en su función integradora de los actos jurídicos, es decir, con un alcance de complementación de las manifestaciones de voluntad que se traduce en deberes específicos de la conducta de las partes.

En palabras de nuestra Corte Suprema de Justicia, Sala Civil, en su genial sentencia del 2 de agosto de 2001, la buena fe objetiva "se traduce en una regla - o norma - orientadora del comportamiento (directiva o modelo tipo conductual) que atañe al dictado de precisos deberes de conducta que, por excelencia, se proyectan en la esfera pre-negocial y negocial, en procura de la satisfacción y salvaguarda de intereses ajenos (deberes de información; de claridad o precisión; de guarda material de la cosa; de reserva o secreto, etc.)"21.

De allí que la doctrina más reconocida afirme al respecto:

En este caso la buena fe, como comportamiento de fidelidad, se sitúa en el mismo plano que el uso o la ley, es decir, adquiere función de norma dispositiva, de ahi su naturaleza objetiva que no se halla basada en la voluntad de las partes,

21 Corte Suprema de Justicia. Sala de Casación Civil. Exp. 6146 (2 de agosto de 2001). 
sino en la adecuación de esa voluntad al principio que inspira y fundamenta el vínculo negocial. [...]

De esta manera el principio de la buena fe sirve para suplir, integrar y corregir el contenido del negocio, en función interpretativa; o lo que es lo mismo, desde otro punto de vista la buena fe interviene en la configuración de la norma del negocio jurídico, situándose en el mismo lugar que los usos del tráfico, o la norma dispositiva, constituyendo por ello, en sí misma una norma dispositiva; fundamentada, por otra parte, en un objetivo criterio de conducta $[. . .]^{22}$.

\section{Por demás, la Sala de Casación Civil de la Corte Suprema sostuvo en providencia reciente:}

[...] cuando las partes realizan una regulación específica de los intereses involucrados en sus esferas dispositivas (negocio jurídico), con apego a la reglamentación normativa vigente, propician, paralelamente, que la ley les brinde el reconocimiento y convalidación de la voluntad declarada, en los términos por los que hayan optado los mismos contratantes. Pero ese posicionamiento les impone, colateralmente, la observancia irrestricta de reglas de conducta que involucran conceptos ligados a la lealtad y buena fe, tanto para sí como para con aquellos que de una u otra forma resultan afectados (Art. 1603 ibídem). La buena fe implica que las personas, cuando acuden a concretar sus negocios, deben honrar sus obligaciones y, en general, asumir para con los demás una conducta leal y plegada a los mandatos de corrección socialmente exigibles. El acatamiento de dichos principios implica para el contratante el sentimiento de proceder como lo hace cualquier ser humano digno de confianza, que honra su palabra, que actúa conforme a las buenas costumbres, que respeta a sus semejantes, que responde con honestidad sus compromisos, aviniéndose, incondicionalmente, a reconocer a sus congéneres lo que les corresponde. Obrar dentro de esos parámetros es prohijar conductas que han sido erigidas como referentes sociales de comportamientos apropiados. Obrar de buena fe es proceder con la rectitud debida, con el respeto esperado, es la actitud correcta y desprovista de elementos de engaño, de fraude o aprovechamiento de debilidades ajenas $[. . .]^{23}$.

Entre nosotros, entonces, con fundamento en los artículos 863 y 871 del Código de Comercio y 1603 del Código Civil, corresponde a las partes de un negocio jurídico cumplir y ejecutar sus prestaciones atendiendo no solo lo que dicta la exégesis de las cláusulas contractuales, sino también, y de manera muy importante, lo que por ser de la naturaleza de las cosas debe cumplirse de buena fe.

22 José Luis De Los Mozos, El principio de la buena fe, sus aplicaciones prácticas en el derecho civil español, op. cit., 45-46.

23 Corte Suprema de Justicia. Sala de Casación Civil. Exp. 11001310302520010045701 (24 de enero de 2011). 
En palabras de González Pérez "cualquiera que sea el tipo de la obligación y la naturaleza de la prestación, el obligado no solo debe realizar lo especialmente previsto, sino todas las consecuencias que sean conformes a la buena fe. Si el obligado [...] no lo hace así y se limita a realizar lo específicamente previsto, no habrá cumplido la obligación"24.

Por ende, el principio de buena fe cumple una función integradora o complementadora del negocio jurídico ${ }^{25}$, en el sentido de precisar las estipulaciones, acotar sus alcances y manifestar prestaciones que si bien pueden no haber sido expresamente convenidas, de acuerdo con la naturaleza del contrato, el alcance de sus prestaciones, los intereses de las partes y las expectativas y móviles conocidos de los contratantes, deben entenderse implícitas o sobreentendidas en el negocio ${ }^{26}$.

Por ello, al paso que las partes de un negocio jurídico están obligadas a cumplir las obligaciones prestacionales específicamente pactadas en el contrato, también deben observar otros deberes jurídicos - los deberes secundarios de conducta-, emanados precisamente del principio de la buena fe, que se denominan también "deberes colaterales", "deberes complementarios" o "deberes contiguos", tales como los de información, protección, consejo, fidelidad o secreto, entre los más relevantes, que aunque no se pacten expresamente entre las partes, se incorporan a los contratos en virtud del principio de buena $\mathrm{fe}^{27}$.

Dichos deberes complementarios no son deberes de jerarquía o categoría distinta de los propios deberes de prestación nacidos del contrato, como quiera que unos y otros apuntan a que el cumplimiento del negocio se realice adecuada y plenamente, en la perspectiva del interés y objetivos de ambas partes. No por otra

24 Jesús González Pérez, El principio general de la buena fe en el derecho administrativo, 74 (1988).

25 Así lo reconoce el tratadista Jorge Suescún Melo, Derecho privado: Estudios de derecho civil y comercial contemporáneo, Tomo I, 445.

26 En esta misma dirección dice la jurisprudencia arbitral: "Esta función integradora del principio de la buena fe ha sido resaltada por la doctrina como una evolución del derecho en las últimas décadas, evolución en este caso basada en la idea de confianza, como elemento básico de las relaciones negociales, lo que ha permitido emplear dicho principio de la buena fe para, entre otras cosas, determinar judicialmente obligaciones conexas con la principal, pero que no han sido pactadas expresamente". Laudo Arbitral. Beneficencia de Cundinamarca vs. Banco Central Hipotecario y Fiduciaria Central. Árbitros: Carlos Lleras de la Fuente, Presidente, Jorge Cubides Camacho y Jorge Suescún Melo (julio 31 del 2000).

27 Arturo Solarte, La buena fe contractual y los deberes secundarios de conducta, Revista Vniversitas, No. 108, 304 (2004). 
razón el profesor Galgano los denomina, sin eufemismos, “deberes de conducta contractual" 28 .

Es más, la denominación deberes, que por demás ha sido discutida por la doctrina, se refiere al hecho de que tienen una aplicación general a todos los negocios jurídicos, pero que tras una concreción se transforman en obligación propiamente dicha, y secundarios, no por su falta de importancia o utilidad, sino porque nacen del principio de la buena fe contractual. De ahí que su denominación sea tan variada y reñida.

\section{El deber de coherencia}

El deber de coherencia es tal vez uno de los más importantes deberes colaterales en la medida en que, como derivación de la buena fe, procura que las partes actúen de conformidad con la voluntad que han exteriorizado y las acciones ejecutadas en el marco del iter contractual, lo que necesariamente genera en la contraparte una expectativa cierta y legítima de ser cumplida.

La coherencia, de acuerdo con lo anunciado, es bipartita. De una parte, su objetivo es salvaguardar la confianza fundada y generada en la parte que actúa conforme a las manifestaciones y actuaciones de la otra, a través de las cuales se guía su relación negocial y, adicionalmente, constituye un reflejo del equilibrio contractual por medio del cual se procura la simetría en el contrato ${ }^{29}$.

La coherencia, como deber secundario de conducta, merece protección judicial. Como lo anota la profesora Mariana Bernal, "[e]l juez debe de un lado sancionar las incoherencias y de otro lado recurrir a un interpretación de la voluntad real de las partes, [...] No es aceptable el comportamiento de una de las partes en la cual por escrito se manifieste un desacuerdo pero el comportamiento lo acepte"30.

En el ordenamiento jurídico colombiano es dable encontrar diferentes instituciones que protegen la coherencia en el campo negocial y que han sido de importante desarrollo jurisprudencial. Dentro de esas manifestaciones es dable destacar la denominada

28 Francesco Galgano, Diritto privato, Ed., Cedam, Padova, 342 (1996).

29 Jorge Suescún Melo, Derecho privado: Estudios de derecho civil y comercial contemporáneo, Tomo I, op. cit., 27.

30 Mariana Bernal Fandiño, El deber de coherencia en los contratos y la regla del venire contra factum propium, op. cit., 26. 
doctrina de los actos propios $^{31}$ que, en línea con el deber enunciado y en palabras del profesor argentino López Mesa, se refiere al hecho de que "[...] nadie puede variar en otros la expectativa de comportamiento futuro" 32 . De este modo, la doctrina se constituye en límite del ejercicio del derecho subjetivo con el propósito de lograr, en el marco de las relaciones contractuales, un comportamiento consecuente y coherente de las personas, justamente como corolario del principio de la buena fe. Por ello la Corte Constitucional ha señalado que "[...] un tema jurídico que tiene como sustento el principio de la buena fe es el del respeto al acto propio, en virtud del cual, las actuaciones de los particulares y las autoridades públicas deberán ceñirse a los postulados de la buena fe. Principio constitucional, que sanciona como inadmisible toda pretensión licita, pero objetivamente contradictoria, con respecto al propio comportamiento efectuado por el sujeto"33.

Pero, claro está, "[...] no basta la mera contradicción de un acto previo con otro posterior [...] es fundamental entender que la base de la doctrina de los actos propios se encuentra en las expectativas legitimas creadas con las actuaciones. Es necesario proteger la planeación y que no se permita que con su incoherencia una parte de un contrato le ocasiones un daño a la otra"34.

Otra de las manifestaciones más importantes del deber de coherencia corresponde al principio de la confianza legítima, el cual procura salvaguardar las expectativas genuinas creadas en el cocontratante. Se trata, claro está de un corolario de la buena fe, ya que ampara las conductas y manifestaciones exteriorizadas respecto de la celebración de un contrato e incluso protege la estabilidad jurídica que de las mismas se pueda derivar.

31 Son tres los requisitos para la aplicación de la teoría, a saber. (i) la existencia de una conducta jurídica anterior, relevante y eficaz, esto es, que haya una acción en el marco de una relación jurídica que genere la confianza de un tercero y que dicha conducta emitida sea eficaz contradiciendo otra conducta posterior que también es contradictoria a aquella; (ii) el ejercicio de un derecho subjetivo por parte de la misma persona que crea la situación litigiosa, en razón a la contradicción - atentatoria de la buena fe - existente entre ambas conductas; y (iii) la identidad del sujeto en el despliegue de las dos conductas.

32 Marcelo López Mesa, La doctrina de los actos propios en la jurisprudencia, Ed. Desalma (1997).

33 Corte Constitucional. Sentencia T-295 de 1999.

34 Mariana Bernal Fandiño, El deber de coherencia en los contratos y la regla del venire contra factum propium, op. cit., 36 .

Ver también: Mariana Bernal Fandiño, La doctrina de los actos propios y la interpretación del contrato, en: Quaestiones Disputatae, No. 2, Ed. Pontificia Universidad Javeriana, 11 y ss. (2010) 
Aunque en nuestro ámbito jurídico la figura de la confianza legítima ha sido ligada principalmente con el derecho público y particularmente en la teoría del acto administrativo y la contratación pública, en tanto se trata de un legado del principio de la buena fe que consagra el artículo 83 de la Constitución Política, el mismo encuentra plena aplicación en el campo del derecho privado, en cuanto "[...] el desconocimiento unilateral de los términos de un acuerdo o convención por alguna de las partes, no solo desconoce el principio de la buena fe y el respeto a los actos propios, sino que también viola el principio de la confianza legítima por no obedecer a una conducta legítima, pues según Larenz, el ordenamiento protege la confianza suscitada en el otro como condición fundamental para vida pacífica y de cooperación" 35 .

\section{El deber de cooperación}

Íntimamente relacionado con el ya enunciado deber de coherencia, se encuentra el deber de cooperación o de solidaridad. Así, "[e]l deber de colaborar exige que, más allá de las diferencias de intereses que existan entre las partes en la ejecución del contrato, se deba evitar toda dificultad facilitando la ejecución del crédito a la otra parte. [...] las partes entre sí tienen el deber de actuar lo mejor posible para el logro del interés del co-contratante. Ello, como bien destaca Kemelmajer de Carlucci, puede implicar ejecutar prestaciones no previstas expresamente; modificar el propio comportamiento; tolerar que la otra parte modifique la prestación; dar aviso de ciertos acontecimientos, etc." 36 . En ese sentido, "[...] el deber de colaboración leal en la ejecución del contrato entre las partes exige al acreedor abstenerse de todo acto $u$ omisión que pueda tener por consecuencia privar a la otra parte de beneficios o ventajas propias del contrato o que agrave injustificadamente el resultado, volviendo más onerosa la situación del deudor"37.

35 Mariana Bernal Fandiño, El deber de coherencia en los contratos y la regla del venire contra factum propium, op. cit., 39.

36 Gustavo Ordoqui Castilla, Buena fe contractual, Ed. Pontificia Universidad Javeriana - Universidad Católica de Uruguay - Ibáñez, 385 (2012).

37 Ibíd. 


\section{PRincipales presupuestos de la CONDICIÓN SIMPLEMENTE POTESTATIVA DE CARÁCTER SUSPENSIVO}

De acuerdo con el artículo 1530 de nuestro Código Civil, "Es obligación condicional la que depende de una condición, esto es, de un acontecimiento futuro, que puede suceder o no".

Aunque la doctrina estima que la definición legal es incompleta, ella consagra los dos elementos básicos y característicos de la condición, a saber: i. hecho futuro y ii. hecho incierto ${ }^{38}$. Al respecto ha enseñado la Corte Suprema de Justicia que "[p]ara la ciencia del derecho privado, únicamente es obligación condicional la que subordina su existencia o extinción a un acontecimiento futuro e incierto. Por tanto los elementos constitutivos de la obligación condicional, son: $1^{\circ}$ la necesidad de un acontecimiento, futuro e incierto; $2^{\circ}$ la sujeción de la obligación a este acontecimiento, y $3^{\circ}$ el carácter voluntario, o sea convencional, de esta dependencia. El acontecimiento futuro e incierto no puede consistir en una obligación sino en un hecho"39.

De acuerdo con el efecto que pueda producir, la condición se clasifica de diferentes maneras. Interesa analizar, de una parte, la denominada condición simplemente potestativa y, de la otra, la llamada condición suspensiva.

\section{A. Condición simplemente potestativa}

La condición potestativa como categoría se encuentra consagrada en el ordenamiento jurídico colombiano bajo el artículo 1534 del Código Civil, el cual establece que "[s]e llama condición potestativa la que depende de la voluntad del acreedor o del deudor; causal la que depende de la voluntad de un tercero o de un acaso; mixta la que en parte depende de la voluntad del acreedor y en parte de la voluntad de un tercero o de un acaso".

De este modo, en lo concerniente a la condición potestativa, ha dicho la Sala de Casación Civil de la Corte Suprema de Justicia colombiana

38 Jorge Cubides Camacho, Obligaciones, Ed. Pontificia Universidad Javeriana, 114 (2009).

39 Corte Suprema de Justicia. Sala de Casación Civil. (mayo de 1938). Sentencia citada en la obra: Jorge Ortega Torres, Comentarios al Código Civil, Ed. Temis, 648 (1973). 
[l]a condición potestativa admite una subclasificación, según la doctrina, en simplemente potestativa y mera o puramente potestativa; la primera supone de parte del obligado no solo una manifestación de voluntad sino la realización de un hecho exterior; la segunda, en cambio, depende exclusivamente de la mera voluntad o capricho de la persona que se obliga, si voluero, si quiero. La condición simplemente potestativa es válida, porque la obligación del deudor se subordina, en parte al menos, a contingencias que no dependen de su solo arbitrio. Por el contrario, la condición mera o puramente potestativa puede ser válida o no según las circunstancias. Si depende de la voluntad del acreedor es válida, sea suspensiva o resolutoria; si depende de la voluntad del deudor también es válida cuando es resolutoria ${ }^{40}$.

\section{De otra parte, en lo que a la condición mixta refiere,}

[s]e entiende que se permita sujetar la obligación a hechos voluntarios que no consistan en el puro arbitrio del deudor, por ejemplo, cuando se condiciona la expresión de la voluntad de este al hecho de un tercero o al acaso (condiciones que el Código llama causales), o cuando el evento incierto depende en parte de la voluntad del deudor y en parte de la de un tercero o del acaso (condiciones no mencionadas por el Código). De allí que el art. 1171 del C. francés, dijera: "La condición mixta es aquella que depende al mismo tiempo de la voluntad de una de las partes contratantes y de la voluntad de un tercero". Obsérvese bien: "de la voluntad de una de las partes..."; nuestro Código tradujo: "de la voluntad del acreedor", cometiendo una notoria impropiedad. Error que tiene como antecedente el art. 1656 a, del Proyecto Inédito, que se inspiró en Pothier ${ }^{41}$.

\section{En esa medida, la condición que pende de la voluntad y elementos} externos a ella (potestativa simple) es, a su vez, una condición mixta en el entendido en que, en razón a lo expuesto, está sujeta no exclusivamente al hecho voluntario del deudor o acreedor, sino también a actos y/o hechos externos a él, sobre los que no tiene dominio ${ }^{42}$.

40 Corte Suprema de Justicia. Sala de Casación Civil. (3 de julio de 1969).

41 Álvaro Pérez Vives, Teoría general de las obligaciones, Ed. Universidad Nacional de Colombia, 587 (1951).

42 De antaño la Sala de Casación Civil de la Corte Suprema de Justicia colombiana ha distinguido entre condición simplemente potestativa y puramente potestativa, como se acabó de ver. Pero, en igual medida, ha reconocido que la llamada simplemente potestativa supone, además de su manifestación de voluntad de la realización de un hecho exterior para la configuración de la condición.

"Desde la doctrina francesa, pasando por la chilena, se ha explicado el anterior principio así: hay dos clases de condiciones potestativas: la simplemente potestativa, que supone de parte del interesado, no solo una manifestación de voluntad, sino la realización de un hecho exterior, vgr., si os casáis, si vendo mi casa; y la puramente potestativa que depende, única y exclusivamente, de la voluntad $y$, por consiguiente se formula de este modo: si voluero, si quiero, si lo juzgo a propósito. La condición simplemente potestativa, es válida. La obligación del deudor, si bien depende de un acto de su voluntad se subordina también, en parte, a contingencias de las que no 


\section{De la siguiente manera lo explica Pérez Vives:}

[...] no se justifica la distinción entre condición potestativa pura y condición potestativa simple, ya que es difícil, si no imposible, hallar una de esta naturaleza que no depende de hechos externos al deudor, al mismo tiempo que de la voluntad de este; por lo cual, vendría a ser condición mixta. Precisamente, si se admite su validez, es por la concurrencia de esos hechos ajenos o exteriores al obligado, con su manifestación de voluntad. Como lo expresó la Corte. "la obligación del deudor, si bien depende de un acto de voluntad se subordina también, en parte, a contingencias de las que no es dueño"43.

\section{B. Condición suspensiva}

A la luz del artículo 1536 de nuestro Código Civil, "La condición se llama suspensiva si, mientras no se cumple, suspende la adquisición de un derecho [...]”. Así, de acuerdo con el artículo 1542 del mismo cuerpo normativo, "No puede exigirse el cumplimiento de la obligación condicional sino verificada la condición totalmente".

Por ello ha dicho la doctrina que la condición suspensiva es aquella de la cual depende el nacimiento o existencia de una obligación o un derecho. Concretamente, se ha definido como el hecho futuro e incierto del que pende la existencia de la obligación ${ }^{44}$.

De este modo, en el estado de pendencia de la condición suspensiva - uno de los tres estados en los que puede encontrarse la condición - se está a la espera del acaecimiento o verificación del hecho futuro e incierto del que depende el nacimiento de la obligación. Sin perjuicio de ello, como enseñan Alessandri y De Gasperi, esta tesis no es absoluta ni concluyente. Para un sector importante de la doctrina, dentro de los que se pueden incluir tratadistas como Colin, Capitant y el propio Alessandri, antes de la comprobación del hecho futuro e incierto existe un germen de obligación, de vínculo jurídico, que implica deberes y responsabilidades para las partes ${ }^{45}$.

es dueño”. Corte Suprema de Justicia. Sala de Casación Civil. (22 de noviembre de 1945).

43 Álvaro Pérez Vives, Teoría general de las obligaciones, op. cit., 588.

44 Guillermo Ospina Fernández, Régimen general de las obligaciones, Ed. Temis, 226 (2005).

45 "Punto muy discutido entre los autores es el relativo a saber en qué momento se forma la obligación condicional, si se forma ella al cumplirse la condición, como creen algunos, o si se forma al momento de convenirse el acto jurídico que la engendra; en otros términos, desde qué momento existe la obligación condicional ante el Derecho entre el deudor y el acreedor. Algunos han creido que la obligación condicional solo existe ante el Derecho desde que la condición se cumple. Pero la generalidad de las opiniones, y a mi entender esta doctrina es más ajustada a la ley, están 
De ahí que en nuestro ordenamiento en la etapa de pendencia se determine, entre otros, que las partes actúen sin transgredir el orden lógico del acontecimiento de los hechos que fundan la ocurrencia de la condición (inc. 3 art. 1538 C.C.); que el deudor condicional está obligado a cuidar la cosa prometida, y que si por su culpa se menoscaba o perece, es obligado a la indemnización de perjuicios (art. 1534 del C.C.); que el germen de derecho del acreedor y el principio de obligación que pesa sobre el deudor son transmisibles por causa de muerte (art. 1549 C.C.).

contestes en sostener que la obligación, y en consecuencia el derecho condicional, se forman desde el momento de celebrarse el contrato que la engendra, y es por eso que desde ese momento, deben concurrir todos los requisitos necesarios para la formación del contrato. Pero si bien el contrato y la obligación condicional se forman en el momento en que las partes han convenido en la obligación de que se trate, el derecho del acreedor condicional, existe solamente en germen, hay un rudimento de derecho que existe en la penumbra, en la incertidumbre de si llegará a ser o no como todos los demás derechos. Hay muchas razones para demostrar que si el derecho existe en germen al tiempo de convertirse el contrato: en primer lugar, la retroactividad de las condiciones; ¿cómo se explicaría el efecto retroactivo de las condiciones si el derecho condicional solo existiera desde el momento en que la condición se ha cumplido? ¿Qué razón habría si la obligación y el derecho nacieran y se formaran al cumplirse la condición, para retrotraer sus efectos a una época anterior a ella? En seguida, ¿cómo se explicaría que el derecho y la obligación condicional pudieran transmitirse a los herederos del deudor y del acreedor, si el derecho y la obligación condicional solo existieran a partir del cumplimiento de la condición? Si solo se transmite lo que se tiene y lo que existe y si el acreedor nada tuviera desde el contrato hasta el cumplimiento de la condición, ¿cómo podría transmitir lo que no tiene? Sin embargo, la ley declara expresamente la transmisión de estos derechos condicionales y de estas obligaciones condicionales. Por otra parte, ¿Cómo se explicaría el derecho del acreedor condicional a solicitar medidas conservativas si ningún derecho tiene antes del cumplimiento de la condición? Finalmente, entre el contrato y el cumplimiento de la condición no puede el deudor desligarse por su sola voluntad del vínculo jurídico, y esto está demostrado una vez más que desde el momento mismo de la celebración del contrato se han producido efectos, ya que si no existieran, podría el deudor liberarse en cualquier momento de la obligación que contrajo. Todas esas razones hacen llegar a la conclusión irrefutable de que la obligación condicional y el derecho condicional existen desde el momento en que el contrato se celebra, si bien es solo un principio de derecho que queda subordinado al evento de que la condición se cumpla. Si se pudiera comparar materialmente con algo esto que acabo de explicar, podría compararse con la existencia natural y legal de las personas. En concepto de la ley una persona no es generalmente persona sino a partir de su nacimiento; pero antes del nacimiento, ¿hay o no un principio de personalidad que la ley reconoce y protege? Evidentemente que lo hay; la ley protege la vida del que está por nacer y protege sus derechos. Lo mismo sucede en materia de obligaciones condicionales; mientras dura el embarazo hay un germen de derecho, y una vez que se produce el nacimiento, o sea la realización de la condición, el germen o principio de derecho se transforma en un derecho. [...] Mientras la condición pende, si bien existe en estado latente la obligación, si bien hay un germen o rudimento de derecho, si bien este está en estado embrionario, y es, por consiguiente, la existencia misma del derecho la que está en suspenso, no puede por eso dejar de reconocerse que existe un derecho, pero no completo no con todos sus atributos, porque es la existencia, la vida del derecho la que está peligrando, de manera que si la condición no se cumple el derecho condicional falla". Arturo Alessandri Rodríguez, Derecho Civil, teoría de las obligaciones, Ed. Imprenta El Esfuerzo, 183-184.

Ver también: Ambrosio Colin \& Henry Capitant, Derecho civil, 3 Teoría general de las obligaciones, Ed. Reus S.A., 343 (1924). 
No solo ello, en el estado de pendencia, mientras acaece la condición, debe actuarse conforme a los designios de la buena fe, esto es que las partes procedan con cortesía y lealtad, cooperación, sin afectar el desarrollo lógico y normal de los hechos, como ya se anticipaba (inc. 3 art. 1538 C.C.) ${ }^{46}$. Conforme a ello, anota Betti que cuando se trata de una obligación condicional las partes deben actuar de buena fe y procurar que no queden fallidas las recíprocas expectativas ${ }^{47}$. En ese sentido, cuando se presenta una condición contractual se genera una situación de confianza que debe salvaguardarse por medio de la buena fe objetiva, particularmente, los deberes colaterales que de ella nacen.

Así, el acreedor del derecho en potencia, o del denominado "germen de derecho", tiene los fundamentos jurídicos suficientes para tomar y ejercer todas las medidas conservatorias destinadas a preservarlo ${ }^{48}$. En esa línea, parecería claro que bajo la hipótesis de que exista una condición simplemente potestativa, la cual como se ha visto pende en fracción del actuar de una de las partes, el contratante, en cuya voluntad reside la realización en fracción del hecho futuro e incierto, debe ejecutarlo, pues de no hacerlo faltaría al deber de cooperación, causándole perjuicios a su co-contratante. Se pasa a analizarlo con mayor detenimiento.

\section{EL DEBER DE COHERENCIA Y COOPERACIÓN EN LA EJECUCIÓN DE LA CONDICIÓN SIMPLEMENTE POTESTATIVA}

Sin lugar a dudas la buena fe, como principio general del derecho, permea cada una de las etapas contractuales. El periodo previo

46 "Con todo, si la persona que debe prestar la asignación, se vale de medios ilícitos para que la condición no pueda cumplirse, o para que la otra persona, de cuya voluntad depende en parte su cumplimiento, no coopere a él, se tendrá por cumplida”. Código Civil Colombiano [CCC]. Ley 57 de 1887. inc. 3 art. 1538. Abril 15 de 1887 (Colombia).

47 Emilio Betti, Teoría general de las obligaciones, Ed. Revista de Derecho Privado, Madrid, 112 (1969).

48 "...] mientras la condición suspensiva no se ha cumplido, no se sabe si el acto jurídico producirá el efecto deseado. Sin embargo, este acto se ha realizado; la relación jurídica a que debe dar origen está, desde este momento, esbozada. No es exacto decir con Pothier que solamente hay una esperanza de derecho [...] El que ha prometido bajo condición suspensiva no puede ya retirar la promesa que ha hecho. El derecho condicional existe en germen. Por consiguiente, le está permitido a aquel en cuyo beneficio ha sido creado tomar todas las medidas de conservación destinadas a defenderlo". Ambrosio Colin \& Henry Capitant, Derecho Civil, 3, Teoría general de las obligaciones, op. cit., 343. 
al nacimiento de las obligaciones y/o de los contratos no escapa a ese imperativo. Por esa razón, en la época en que la condición está pendiente debe actuarse con honestidad, corrección, lealtad, de buena fe para su efectivo cumplimiento sin importar si ello pende del azar, de un tercero o de alguna de las partes.

De ese modo, los contratantes, y no solo quien tiene sobre su voluntad el hecho potestativo, deben actuar de buena fe y con diligencia sin obstaculizar el orden lógico de los hechos que permitan la realización de la condición.

En efecto, explica el profesor español Diez Picazo estudiando los deberes y responsabilidades en el periodo pendiente de la condición suspensiva que "[d]esde el instante mismo de la celebración del negocio jurídico creador de la relación y durante la fase de pendencia de la condición, al deudor le son impuestos ya unos deberes y asume una determina responsabilidad. [...] el deudor soporta también el deber de no incidir con su comportamiento sobre el cumplimiento de la condición, así como no obstaculizarlo" 49 .

En esa misma línea, dentro de la doctrina patria se destacan las expresiones sobre este asunto de Ospina Fernández quien sostiene que "[d]el hecho de que exista un principio de obligación también se sigue consecuencias, [...] 1) El deudor no se encuentra completamente desvinculado de su acreedor y debe, por consiguiente, observar una conducta tal que no perjudique el nacimiento futuro de su obligación; si por su culpa la condición falla, se entenderá cumplida (art. 1538, inc. $\left.3^{\circ}\right)^{\prime \prime}{ }^{50}$.

En esa medida, primero, si bien la obligación no ha nacido, las partes tienen un vínculo pre-jurídico que acarrea deberes y responsabilidades. De ahí que Colin y Capitant afirmen que no hay solo una esperanza de ver nacer el derecho bajo la hipótesis en la cual se está a la espera del cumplimiento de la condición suspensiva, como sostiene la gran mayoría de tratadistas franceses, sino que ya el acto jurídico está delineado y los contratantes están atados en parte a él ${ }^{51}$. De ahí que a la luz del inciso 3 del artículo 1538 de

49 Luis Diez-Picazo, Fundamentos del derecho civil patrimonial, II Relaciones obligatorias, Ed. Civitas, 356-357 (1996).

50 Guillermo Ospina Fernández, Régimen general de las obligaciones, Ed. Temis, 232 (2005).

51 Ambrosio Colin \& Henry Capitant, Derecho Civil, 3 Teoría general de las obligaciones, op. cit., 343 y ss.

"Divídese la doctrina en punto a la apreciación del valor de la obligación subordinada a una con- 
nuestro Código Civil, se establezca como imperiosa la cooperación de las partes y/o parte para el cumplimiento de la condición y, en esa medida, se sancione jurídicamente, con el cumplimiento de la condición, el hecho en virtud del cual la persona que debe prestar la asignación perjudique de manera ilícita el acaecimiento del hecho futuro e incierto. En los siguientes términos lo establece el artículo señalado: "Con todo, si la persona que debe prestar la asignación, se vale de medios ilícitos para que la condición no pueda cumplirse, o para que la otra persona, de cuya voluntad depende en parte su cumplimiento, no coopere a él, se tendrá por cumplida".

Así, es predicable que en esta etapa de pendencia existe si bien no un vínculo jurídico entre las partes, sí una relación pre-jurídica que envuelve deberes y responsabilidades propias del acto jurídico que han trazado, siendo el bien jurídico protegido el derecho en potencia que envuelve la obligación condicional.

Por ello, con razón certera expresa el profesor Ordoqui, en un acápite de su célebre obra sobre la buena fe, titulado Buena fe y la condición, que

[1] as partes en la etapa de la espera deben actuar de buena fe, con corrección y lealtad, sin afectar el desarrollo normal de los hechos. El deber de actuar de buena fe y con corrección refiere a las dos partes. [...] Betti dice que cuando la obligación está sujeta a condición las partes deben actuar de buena fe y procu-

dición suspensiva. Los escritores franceses, salvo excepciones, partiendo del principio romano: Nihil adhucdebetur, sed spesestdebitumiri, enseñan que, pendiente la condición, la obligación no existe. Aquí, la condición, a diferencia del término, suspende la constitución del derecho. Solo existe la esperanza de verlo nacer algún día. En consecuencia ninguno de los efectos propios de las obligaciones deben producirse. El futuro acreedor, por su parte, no posee sino la 'esperanza' de llegar a serlo realmente. Y es en este carácter en el que la ley presta su protección. Como nihil interimdebetur no puede accionar. En este punto unos dicen: no existe vínculo jurídico, el acreedor nada puede exigir de quien nada le debe. En el derecho italiano Giorgi dice: 'Hay sin embargo, un vínculo jurídico que tiene por objeto la esperanza de aquella obligación (spesdebitumiri), y confiere al acreedor ciertos derechos; podría considerarse como una obligación menos perfecta y preparatoria de una eficacia propia y no privada de valor patrimonial'. Tal es lo enseñado por Savigny y seguido por Zachariae, Aubry y Rau, Duranton, Demolombe, Marcadé, Laurent, Esmein, Radouant y Gabolde in Planiol y Ripert y Larombière. Según el artículo 1181 del Código Civil francés, la condición suspensiva solo retarda la ejecución, no suspende la existencia de la obligación. Aubry y Rau critican la redacción del precepto, porque, así como está, se presta a confundir el efecto de esta condición con el del término. Escritores posteriores, como Colin y Capitant, partiendo del principio de que el que ha prometido bajo condición suspensiva no puede y a retirar su promesa, estiman que no es exacto decir con Pothier que solamente hay una esperanza de derecho: non dum debetur ses spesde bitum iri. El acto jurídico está realizado; la relación jurídica a que el acto debe dar origen está esbozado [...]". Luis De Gásperi. Tratado de las Obligaciones, en el Derecho Civil paraguayo y argentino, Vol. I, Parte General, Ed. Depalma, 385-389 (1945). 
rar que no queden fallidas las reciprocas expectativas. Cuando en el contrato aparece una "condición" (acontecimiento futuro e incierto del que se hace depender el efecto de un contrato) se genera lo que se denomina "situación de expectativa". Es un interés inicial jurídicamente reconocido pero con miras a una evolución posterior hacia una situación final. Mientras no se conoce si ocurrió o no el hecho previsto como condición, y se transcurre por la situación de expectativa, las partes deben asumir una conducta acorde a la buena fe (objetiva), respetando recíprocamente sus legítimas expectativas ${ }^{52}$.

De ahí que pueda afirmarse, dando respuesta a la pregunta propuesta, que siempre que exista una esperanza cierta y fundada, una legítima expectativa de celebración de contrato, instituida por quien de su voluntad depende en fracción el acaecimiento de la condición sobre su co-contratante, forzosamente habrá que, en virtud de los deberes de coherencia y cooperación - obligación en el caso concreto-, ejecutar la fracción de condición por parte de quien, ya no por voluntad, tiene que efectuarla.

La cuestión es trascendental en la medida en que si el incumplimiento de la condición se da por la falta exclusiva del hecho de quien depende parte de la condición, esta, en virtud de los deberes colaterales y del artículo 1538 del C.C., se tendrá por cumplida, por lo se podrían reclamar los perjuicios derivados del contrato, si es el caso. De lo contrario se podrán reclamar los perjuicios que eventualmente hayan acaecido en la etapa precontractual.

Es también significativo resaltar el valor del principio de la confianza legítima, el cual, en el caso sub examine, se concreta en lo que se ha llamado la legítima expectativa, presupuesto necesario para exigir el cumplimiento de la fracción de la condición simplemente potestativa, suspensiva y pendiente que está en cabeza de la parte obligada, y que se verifica, a la luz de lo indicado por nuestra Sala de Casación Civil de la Corte Suprema de Justicia — en aplicación del principio en el derecho civil-, cuando se observa "[...] a) un acto susceptible de infundir confianza y crear esperanzas fundadas; b) una situación preexistente generatriz de una expectativa verosímil, razonable y legítima basada en la confianza que inspira la autoridad

52 Gustavo Ordoqui Castilla, Buena fe contractual, Ed. Pontificia Universidad Javeriana - Universidad Católica de Uruguay, 430 (2012). 
con su conducta sobre su mantenimiento o estabilidad; y c) una actuación de buena fe del sujeto"53.

De este modo, será el juzgador quien deba, de una parte, constatar la existencia de la condición suspensiva, simplemente potestativa y pendiente en cabeza del deudor y, de la otra, que el obligado ha generado con sus actos una expectativa cierta de que realizará los actos destinados a la celebración del negocio jurídico y que en ese sentido su co-contratante ha actuado de buena fe.

53 Corte Suprema de Justicia. Sala de Casación Civil. Exp. 11001-02-03-000-2005-00251-01 (25 de junio de 2000). 


\section{CONCLUSIón}

De acuerdo con lo estudiado, es dable concluir que en el caso de existir una obligación sujeta a una condición suspensiva, pendiente y simplemente potestativa, en la cual el obligado es la parte sobre la cual pende una porción de la condición, este, el obligado, tendrá que cumplirla en la medida en que, en virtud del artículo 1538 del C.C. $\mathrm{y}$, preponderantemente, de los deberes de coherencia y cooperación, le corresponde desplegar los actos tendientes a la consecución del fin común concertado entre las partes siempre que haya generado una legítima expectativa en su co-contratante.

Para esos efectos, será el juzgador quien, bajo el análisis del caso concreto, determinará que se han presentado los presupuestos necesarios que dan lugar a la determinación de que existe una legítima expectativa creada, que en esa línea no se actuó congruente y lógicamente y que se ha trasgredido el deber de coherencia, de un lado, y/o del otro, que la parte sobre la cual dependía un segmento de la condición no colaboró en el desarrollo de la acción u omisión que le correspondía efectuar para que dicha condición se cumpliera. 


\section{BIBLIOGRAFÍA}

\section{Doctrina}

Álvaro Pérez Vives, Teoría general de las obligaciones, Ed. Universidad Nacional de Colombia (1951).

Ambrosio Colin \& Henry Capitant, Derecho civil, 3 Teoría general de las obligaciones, Ed. Reus S.A. (1924).

Arturo Alessandri Rodríguez, Derecho civil, teoría de las obligaciones, Ed. Imprenta El esfuerzo (1983).

Arturo Solarte, La buena fe contractual y los deberes secundarios de conducta, Revista Vniversitas, No. 108 (2004).

Arturo Valencia Zea \& Álvaro Ortiz Monsalve, De las obligaciones, Tomo III, Ed. Temis (2010).

De Page, Traité elementaire de droit civil, T. II (1964).

Demolombe, Cours de droit civil, T. XII, No. 387 (1968).

Francesco Galgano, Diritto privato, Ed. Cedam, Padova (1996).

Franz Wieacker, El principio general de la buena fe, Ed. Civitas S.A. (1997).

Guillermo Ospina Fernández \& Eduardo Ospina Acosta, Teoría general del contrato y del negocio jurídico, Ed. Temis (2000).

Guillermo Ospina Fernández, Régimen general de las obligaciones, Ed. Temis (2005).

Gustavo Ordoqui Castilla, Buena fe contractual, Ed. Pontificia Universidad Javeriana - Universidad Católica de Uruguay - Ibáñez (2012).

Jean Francois Romain, Théorie critique du principegénérale de bonnefoi en droit privé, Ed. Bruylsant, Bruxelles (2000).

Jesús González Pérez, El principio general de la buena fe en el derecho administrativo, Civitas, Madrid (1988).

Jorge Cubides Camacho, Obligaciones, Ed. Pontificia Universidad Javeriana, Bogotá (2009).

Jorge Ortega Torres, Comentarios al Código Civil, Ed. Temis, Bogotá (1973).

Jorge Suescún Melo, Derecho privado: Estudios de Derecho Civil y Comercial Contemporáneo, Tomo I, Universidad de los Andes - Legis, Bogotá (2003).

José Luis De Los Mozos, El principio de la buena fe, sus aplicaciones prácticas en el derecho civil español, Ed. Bosch (1965).

Lord Mansfield, El concepto de la buena fe en los contratos, Revista de la Academia Colombiana de Jurisprudencia, No. 324 (diciembre del 2003).

Luis De Gásperi, Tratado de las obligaciones, en el derecho civil paraguayo y argentino, Vol. I, Parte general, Ed. Depalma (1945).

Luis Diez-Picazo, Fundamentos del derecho civil patrimonial, II Relaciones Obligatorias, 
Ed. Civitas (1996).

Marcelo López Mesa, La doctrina de los actos propios en la jurisprudencia, Ed. Desalma (1997).

Marina Bernal Fandiño El deber de coherencia en los contratos y la regla del venire contra factum proprium, en: Quaestiones Disputatae 1, Ed., Pontificia Universidad Javeriana (2010).

- La doctrina de los actos propios y la interpretación del contrato, en: Quaestiones Disputatae 2, Ed. Pontificia Universidad Javeriana (2010).

Mosset Iturraspe, Contrato simulado y fraudulento, T. II (2001).

Nelly Dora Louzán De Solimano, La buena fe en el derecho romano, en: Tratado de la buena fe en el derecho, Tomo I, Ed. La Ley (2004).

René Demogue, Traité des obligations, T. VI (1931).

Viviana Kluger, "Una mirada hacia atrás: de Roma a la codificación. El recorrido histórico de la buena fe", en: Tratado de la buena fe en el derecho, Tomo I. Ed. La Ley (2004).

\section{Leyes}

Código Civil Colombiano [CCC]. Ley 57 de 1887. Abril 15 de 1887 (Colombia).

\section{Jurisprudencia colombiana}

Corte Suprema de Justicia. Sala de Casación Civil. Sentencia del 22 de noviembre de 1945.

Corte Suprema de Justicia. Sala de Casación Civil. Sentencia 3 de julio de 1969.

Corte Suprema de Justicia. Sala de Casación Civil.Exp. 11001-02-03-000-2005-00251-01 (25 de junio de 2000).

Corte Suprema de Justicia. Sala de Casación Civil. Exp. 5372 (9 de agosto de 2000).

Corte Suprema de Justicia. Sala de Casación Civil. Exp. 6146 (2 de agosto de 2001).

Corte Suprema de Justicia. Sala de Casación Civil. Expediente 1997-9124 02 (2 de Febrero de 2005).

Corte Suprema de Justicia. Sala de Casación Civil. Exp. 254.01 (9 de agosto de 2007).

Corte Suprema de Justicia. Sala de Casación Civil. Exp. 11001310302520010045701 (24 de Enero de 2011).

Corte Constitucional. Sentencia T-295 de 1999.

Corte Constitucional de Colombia. Sentencia C-007 de 2002.

Corte Constitucional de Colombia. Sentencia C-1194 de 2008.

Laudo Arbitral. Beneficencia de Cundinamarca vs. Banco Central Hipotecario y Fiduciaria Central. Julio 31 de 2000; S.A. Árbitros: Carlos Lleras de la Fuente, Presidente, Jorge Cubides Camacho y Jorge Suescún Melo. 